\title{
Current Practices of Thyroid Fine-Needle Aspiration in Asia: A Missing Voice
}

\author{
Andrey Bychkov · Kennichi Kakudo ${ }^{1} \cdot$ SoonWon Hong ${ }^{2}$ \\ Department of Pathology, Faculty of Medicine, Chulalongkorn University, Bangkok, Thailand: \\ 'Department of Pathology, Nara Hospital, Kindai University Faculty of Medicine, Nara, Japan; \\ ${ }^{2}$ Department of Pathology, Yonsei University College of Medicine, Seoul, Korea
}

Journal of Pathology and Translational Medicine (JPTM) is pleased to announce a special issue devoted to the current practices of thyroid fine-needle aspiration (FNA) cytology in Asian countries as a joint effort of members of the Working Group of Asian Thyroid FNA Cytology. Currently, this growing network of Asian thyroid pathologists includes representatives from China, India, Japan, the Philippines, South Korea, Taiwan, Thailand, Turkey, and Vietnam.

Asia, as the largest and most populous continent, comprises several geographic regions with notable ethnic, cultural and religious diversity. The different levels and pace of economic growth within these regions determines the development of local health systems. Most Asian countries are well integrated into the modern international medical community. Contemporary practices in various fields of medicine were established under a strong Western influence. On the other hand, Asian philosophy, traditional Chinese medicine, Ayurveda, and other conventional medical practices with deep historical roots are often integrated into advanced medical approaches. $^{1,2}$

Consistent with its huge population, the Asian continent is the largest contributor to the worldwide prevalence of thyroid cancer. According to the GLOBOCAN estimates, $48 \%$ of all new thyroid cancer cases are diagnosed in Asia. ${ }^{3}$ In addition, the absolute number of patients with thyroid cancer increases each year, and this growth has recently been labeled a thyroid cancer epidemic,

\section{Corresponding Author}

Andrey Bychkov, MD, PhD

Department of Pathology, Faculty of Medicine, Chulalongkorn University, Rama IV Rd.

Pathumwan, Bangkok 10330, Thailand

Tel: +66-2-256-4235, Fax: +66-2-652-4208, E-mail: andrey.b@chula.ac.th

Received: September 14, 2017 Accepted: September 25, 2017 due to unexpectedly high increases compared to estimates. ${ }^{4}$ South Korea is the best example of this thyroid cancer "epidemic," which has been proven to be largely caused by opportunistic screening. ${ }^{5}$ The same epidemic in many Western countries with a growing incidence of thyroid cancer was later attributed to opportunistic screening also. ${ }^{6}$ As a result of these epidemiological shifts, thyroid cancer and thyroid nodules have attracted considerable attention from the medical community worldwide.

Leading medical centers in well-developed Asian countries have promoted innovative approaches and disseminated highquality evidence, which has profoundly influenced international practice. ${ }^{78}$ Numerous publications from Japan and Korea have laid the ground for national guidelines on the management of thyroid cancer and thyroid nodules, which are finely tuned to the local settings. ${ }^{9,10}$ At the same time, guidelines from less advanced Asian countries largely rely on international recommendations partially adjusted to lower economic standards. ${ }^{11-13}$

Thyroid FNA is a mainstay of preoperative diagnosis of thyroid nodules, which drives further decision making. ${ }^{14}$ This simple procedure is available globally and has been accepted as the first-line intervention in the workup of thyroid nodules, which can significantly reduce unnecessary surgery. Unlike in gynecologic cytopathology, evaluation of thyroid FNA is usually performed by surgical pathologists who tended to apply their own classification schemes used in histopathologic diagnosis of thyroid nodules. As a result, cytologic diagnoses applied to thyroid FNAs were not uniform and clear, but rather variable and vague. Furthermore, a substantial number of samples are found to be uncertain, indeterminate, equivocal, or suspicious, which can create confusion for the clinicians with regard to treatment planning.

In the effort to standardize thyroid cytologic terminology and 
to improve communication between pathologists and clinicians, a new reporting system encompassing six diagnostic categories was proposed around 10 years ago. ${ }^{15}$ Since that time, the Bethesda System for Reporting Thyroid Cytopathology (TBSRTC) has received universal acclaim and has been endorsed by numerous national and international societies in the fields of endocrinology, thyroidology, and cytopathology. ${ }^{16}$ Beyond TBSRTC, several countries, including the UK, Italy, and Japan, have established their own systems for reporting thyroid cytopathology. ${ }^{17-19} \mathrm{Nev}-$ ertheless, the terminology used in non-Bethesda reporting systems is easily adjustable to Bethesda diagnostic categories, which is important for comparison.

Each of the modern systems for reporting thyroid cytopathology provides important statistical outputs, which serve as the quality control criteria. These criteria include (1) distribution of thyroid FNA samples by diagnostic category; (2) resection rate (RR), measured as a ratio of surgically excised nodules to all sampled thyroid nodules within a certain category; and (3) risk of malignancy (ROM) or the percentage of malignant nodules among all FNAs. ROM is important because it indicates the necessity of surgical treatment. The original TBSRTC estimated ROM ranges for diagnostic categories based on preceding literature. ${ }^{15}$ These estimates were further modified in meta-analyses to provide the actual ROM, summarized from the numerous single- or multi-center studies. ${ }^{20-23}$

Most meta-analyses on thyroid FNA and TBSRTC have not included Asian publications. ${ }^{20-22}$ Only one meta-analysis included a fair number of original studies from Turkey, Korea, and Arabic countries. ${ }^{23}$ In fact, experience with thyroid FNA in Asia has been extensively reported. Recently, the results of a nationwide study covering more than 42,000 FNAs were presented by the Korean Society of Endocrine Pathologists. ${ }^{24}$ Japanese institutions have also shared their experience with the Japanese system of reporting thyroid FNA. ${ }^{18}$ There is a growing number of publications from India and China. Reports on thyroid cytology from Southeast Asia are less abundant and often non-systematic. Notwithstanding, we should note that even low-resource countries, for example, Bangladesh and Nepal, have been able to publish their experience with thyroid FNA. ${ }^{25,26}$ Once again, despite the efforts of Asian cytopathologists to share their data with the international community, their voice has not been recognized. Hopefully, output data on the use of TBSRTC from major Asian countries summarized in this special issue will contribute to future meta-analyses of the Bethesda system.

An important lesson learned after comparison of Asian and Western series is that the Asian experience varies in several aspects. Thyroid FNA studies disclosed low RR and high ROM for indeterminate nodules in Asian practice. ${ }^{27}$ This could be explained by

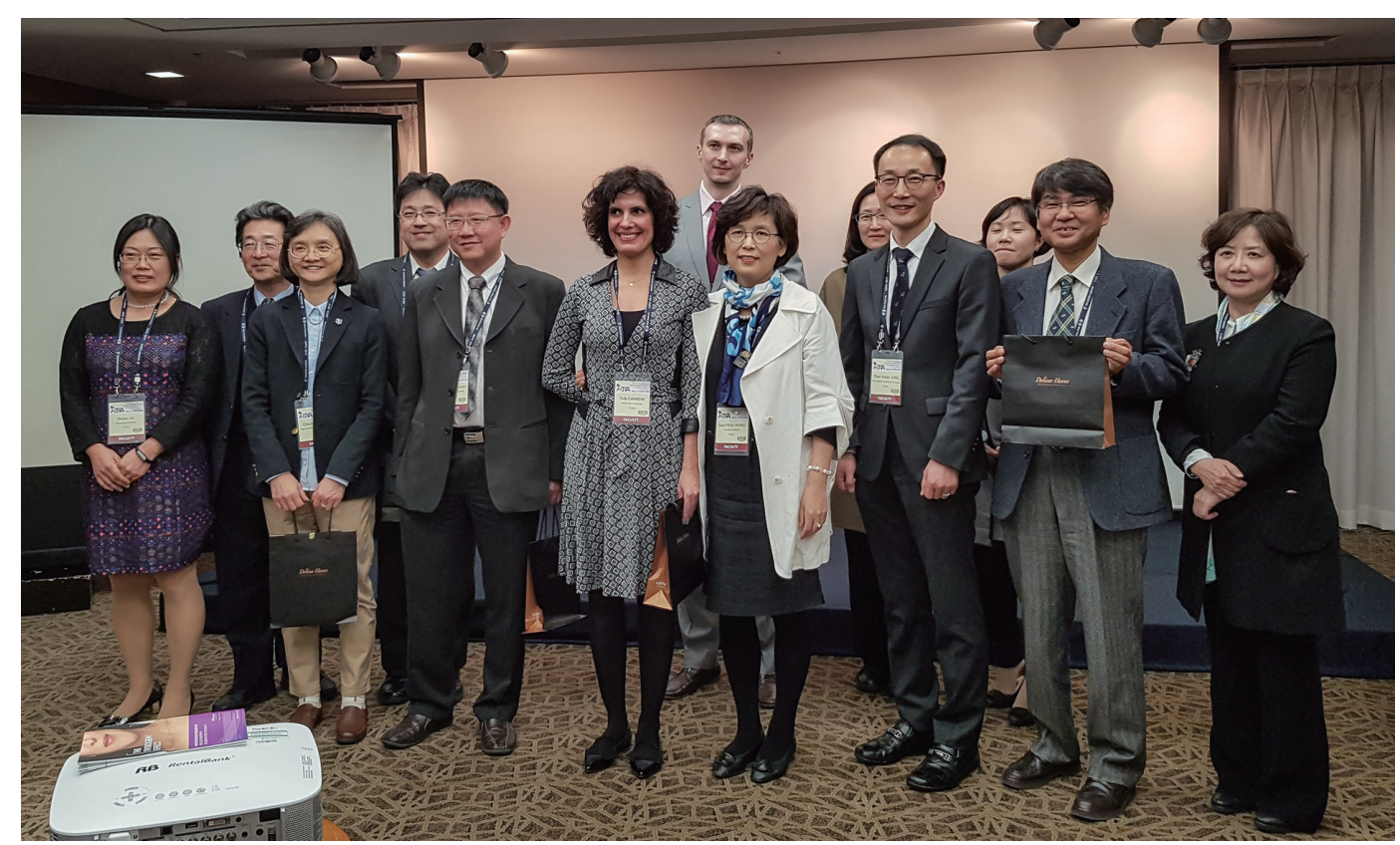

Fig. 1. Members of the Working Group of Asian Thyroid FNA Cytology and hosts during the inaugural meeting of the 12th Asia and Oceania Thyroid Association (AOTA) congress in Busan, Korea (March 16, 2017). FNA, fine-needle aspiration. Left-to-right: Z. Liu (China), K. Kakudo (Japan), C.R. Lai (Taiwan), S. Satoh (Japan), S. Keelawat (Thailand), S. Canberk (Turkey), A. Bychkov (Thailand), S.W. Hong (Korea), D.E. Song (Korea), C.K. Jung (Korea), H.J. Kwon (Korea), M. Hirokawa (Japan), H.K. Chang (Korea). 
the more conservative management approach for indolent thyroid tumors compared to Western practice. ${ }^{28}$ As a result, borderline thyroid tumors, such as noninvasive follicular thyroid neoplasm with papillary-like nuclear features (NIFTP) and well-differentiated tumor of uncertain malignant potential, are histologically rare in Asian countries. ${ }^{29,30}$ These differences are not acknowledged worldwide, which continues to create confusion among experts due to this lack of communication. It should be reiterated that the Asian continent is a major contributor to the global prevalence of thyroid cancer, and that local experience cannot be ignored.

International communication is a key factor in disseminating knowledge and staying up-to-date. There are several international forums held annually for pathologists in Asia, but until recently there were no active well-established networks for those practicing within the thyroid niche. The Working Group of Asian Thyroid FNA Cytology was established recently to promote communication among Asian pathologists and cytopathologists, to share experience in Asian practice, and to conduct multi-institutional studies. An inaugural meeting took place at the 12th Asia and Oceania Thyroid Association (AOTA) Congress in Busan, Korea on March 16, 2017 (Fig. 1). Despite its recent formation, several achievements have resulted from this joint effort. Senior group members released a book Thyroid FNA Cytology: Differential Diagnoses and Pitfalls, which was published in 2016 as the first English language textbook on thyroid FNA cytology from Asia. ${ }^{31}$ Several authors contributed to a special NIFTP issue of the Journal of Basic and Clinical Medicine. ${ }^{32-35}$ More original studies and reviews have been published ${ }^{28,29,36}$ or are currently in process.

Presented herein is a collection of articles on the current practices of thyroid FNA cytology in Asian countries that highlights important aspects of this diagnostic technique, including details on operators and readers, sampling and preparation, and reporting systems and audit programs. Also included are original data collected from the authors of previous publications and statistics from literature review. The authors wish to thank JPTM for hosting this special issue. We hope that our contemporary reviews will serve as a useful reference for a wide variety of specialists involved in the management of patients with thyroid nodules and thyroid cancer.

\section{Conflicts of Interest}

No potential conflict of interest relevant to this article was reported.

\section{REFERENCES}

1. Dong J. The relationship between traditional Chinese medicine and modern medicine. Evid Based Complement Alternat Med 2013; 2013: 153148.

2. Shrivastava SR, Shrivastava PS, Ramasamy J. Mainstreaming of Ayurveda, Yoga, Naturopathy, Unani, Siddha, and Homeopathy with the health care delivery system in India. J Tradit Complement Med 2015; 5: 116-8.

3. Ferlay J, Soerjomataram I, Ervik M, et al. GLOBOCAN 2012 v1.0, Cancer incidence and mortality worldwide: IARC CancerBase No. 11 [Internet]. Lyon: International Agency for Research on Cancer, 2013 [cited 2016 Oct 18]. Available from: http:/ / globocan.iarc.fr.

4. Roman BR, Morris LG, Davies L. The thyroid cancer epidemic, 2017 perspective. Curr Opin Endocrinol Diabetes Obes 2017; 24: 332-6.

5. Ahn HS, Kim HJ, Welch HG. Korea's thyroid-cancer "epidemic": screening and overdiagnosis. N Engl J Med 2014; 371: 1765-7.

6. Vaccarella S, Franceschi S, Bray F, Wild CP, Plummer M, Dal Maso L. Worldwide thyroid-cancer epidemic? The increasing impact of overdiagnosis. N Engl J Med 2016; 375: 614-7.

7. Ito $Y$, Uruno T, Nakano K, et al. An observation trial without surgical treatment in patients with papillary microcarcinoma of the thyroid. Thyroid 2003; 13: 381-7.

8. Leboulleux S, Tuttle RM, Pacini F, Schlumberger M. Papillary thyroid microcarcinoma: time to shift from surgery to active surveillance? Lancet Diabetes Endocrinol 2016; 4: 933-42.

9. Japan Thyroid Association. Guidelines for clinical practice for the management of thyroid nodules in Japan 2013. Tokyo: Nankodo Co., Ltd., 2013.

10. Yi KH. The revised 2016 Korean Thyroid Association guidelines for thyroid nodules and cancers: differences from the 2015 American Thyroid Association guidelines. Endocrinol Metab (Seoul) 2016; 31: 373-8.

11. Chindavijak S, Panchan V, Chaiwerawattana A, Imsamran W. Guidelines for the diagnosis and treatment of thyroid cancer. Bangkok: Kosit Press Co., Ltd., 2015.

12. Sison CM, Obaldo J, Matsuo J, Uy GL, Jaring C. University of the Philippines - Philippine General Hospital revised clinical practice guidelines for the management of well-differentiated thyroid carcinoma of follicular cell origin. J Asean Fed Endocr Soc 2012; 27: 49-61.

13. Unnikrishnan AG, Kalra S, Baruah M, et al. Endocrine Society of India management guidelines for patients with thyroid nodules: a position statement. Indian J Endocrinol Metab 2011; 15: 2-8.

14. Haugen BR, Alexander EK, Bible KC, et al. 2015 American Thyroid Association management guidelines for adult patients with thyroid 
nodules and differentiated thyroid cancer: the American Thyroid Association Guidelines Task Force on Thyroid Nodules and Differentiated Thyroid Cancer. Thyroid 2016; 26: 1-133.

15. Cibas ES, Ali SZ; NCI Thyroid FNA State of the Science Conference. The Bethesda System For Reporting Thyroid Cytopathology. Am J Clin Pathol 2009; 132: 658-65.

16. Pusztaszeri M, Rossi ED, Auger M, et al. The Bethesda System for Reporting Thyroid Cytopathology: proposed modifications and updates for the second edition from an international panel. Acta Cytol 2016; 60: 399-405.

17. Cross P, Chandra A, Giles T, et al. Guidance on the reporting of thyroid cytology specimens. 2nd ed. London: Royal College of Pathologists, 2016.

18. Kakudo K, Kameyama K, Miyauchi A, Nakamura H. Introducing the reporting system for thyroid fine-needle aspiration cytology according to the new guidelines of the Japan Thyroid Association. Endocr J 2014; 61: 539-52.

19. Nardi F, Basolo F, Crescenzi A, et al. Italian consensus for the classification and reporting of thyroid cytology. J Endocrinol Invest 2014; 37: 593-9.

20. Bongiovanni M, Spitale A, Faquin WC, Mazzucchelli L, Baloch ZW. The Bethesda System for Reporting Thyroid Cytopathology: a meta-analysis. Acta Cytol 2012; 56: 333-9.

21. Krauss EA, Mahon M, Fede JM, Zhang L. Application of the Bethesda classification for thyroid fine-needle aspiration: institutional experience and meta-analysis. Arch Pathol Lab Med 2016; 140: 1121-31.

22. Sheffield BS, Masoudi H, Walker B, Wiseman SM. Preoperative diagnosis of thyroid nodules using the Bethesda System for Reporting Thyroid Cytopathology: a comprehensive review and meta-analysis. Expert Rev Endocrinol Metab 2014; 9: 97-110.

23. Straccia P, Rossi ED, Bizzarro T, et al. A meta-analytic review of the Bethesda System for Reporting Thyroid Cytopathology: has the rate of malignancy in indeterminate lesions been underestimated? Cancer Cytopathol 2015; 123: 713-22.

24. Kim M, Park HJ, Min HS, et al. The use of the Bethesda System for Reporting Thyroid Cytopathology in Korea: a nationwide multicenter survey by the Korean Society of Endocrine Pathologists. J Pathol Transl Med 2017; 51: 410-7.

25. Choudhary PK, Nepal N, Mainali N, Meenakshi B. Implementation of Bethesda system in thyroid aspirate: a cyto-histopathological correlation study. J Pathol Nepal 2016; 6: 902-5.
26. Hassan MQ, Hasanat MA, Fariduddin M, et al. Fine needle aspiration cytological diagnosis of thyroid nodule with its clinical correlation. Bangabandhu Sheikh Mujib Med Univ J 2013; 6: 108-15.

27. Kakudo K. How to handle borderline/precursor thyroid tumors in management of patients with thyroid nodules. Gland Surg 2017 Aug 2 [Epub]. https://doi.org/10.21037/gs.2017.08.02.

28. Kakudo K, Higuchi M, Hirokawa M, Satoh S, Jung CK, Bychkov A. Thyroid FNA cytology in Asian practice-Active surveillance for indeterminate thyroid nodules reduces overtreatment of thyroid carcinoma. Cytopathology 2017 [Epub]. https://doi.org/10.1111/ cyt.12491.

29. Bychkov A, Hirokawa M, Jung CK, et al. Low rate of noninvasive follicular thyroid neoplasm with papillary-like nuclear features in Asian practice. Thyroid 2017; 27: 983-4.

30. Liu Z, Zhou G, Nakamura M, et al. Encapsulated follicular thyroid tumor with equivocal nuclear changes, so-called well-differentiated tumor of uncertain malignant potential: a morphological, immunohistochemical, and molecular appraisal. Cancer Sci 2011; 102: 288-94.

31. Kakudo K, Liu Z, Hirokawa M. Thyroid FNA cytology: differential diagnoses and pitfalls. Nara: Kakudo Medical Education, 2016.

32. Canberk S, Baloch ZW, Ince U, Schmitt F. Diagnosis of non-invasive follicular tumor with papillary-like nuclear features (NIFTP): a practice changer for thyroid fine-needle aspiration interpretation. J Basic Clin Med 2017; 6: 38-43.

33. Jung CK, Kim C. Effect of lowering the diagnostic threshold for encapsulated follicular variant of papillary thyroid carcinoma on the prevalence of non-invasive follicular thyroid neoplasm with papillary-like nuclear features: a single-institution experience in Korea. J Basic Clin Med 2017; 6: 26-8.

34. Kakudo K. Unsettled issues in non-invasive encapsulated/wellcircumscribed follicular thyroid neoplasm with papillary-like nuclear features (NIFTP) and precursor thyroid tumors. J Basic Clin Med 2017; 6: 3-7.

35. Kakudo K, Liu Z, Satoh S, Higuchi M, Hirokawa M. Non-invasive follicular thyroid neoploasm with papillary-like nuclear features (NIFTP): diagnosis and differential diagnoses. J Basic Clin Med 2017; 6: 14-21.

36. Bychkov A, Keelawat S, Agarwal S, et al. Impact of noninvasive follicular thyroid neoplasm with papillary-like nuclear features on the Bethesda System for Reporting Thyroid Cytopathology: a multiinstitutional study in five Asian countries. Pathology. Forthcoming. 